\title{
Student Discourse, an Effective Way of Learning Mathematics: Case Study in Bongo Senior High School
}

\author{
Isaac Azure ${ }^{1}$, Louis Doabil ${ }^{2}$ \\ ${ }^{1}$ Department of Basic Education, Regentropfen College of Applied Sciences, Bolgatanga, Ghana \\ ${ }^{2}$ Ghana Institute of Management \& Public Administration, Business School, Achimota, Accra, Ghana
}

Email address:

azureike@yahoo.com (I. Azure), mpaambalouis@yahoo.com (L. Doabil)

\section{To cite this article:}

Isaac Azure, Louis Doabil. Student Discourse, an Effective Way of Learning Mathematics: Case Study in Bongo Senior High School. International Journal of Secondary Education. Vol. 7, No. 2, 2019, pp. 37-43. doi: 10.11648/j.ijsedu.20190702.13

Received: April 21, 2019; Accepted: June 5, 2019; Published: June 19, 2019

\begin{abstract}
Mathematics is seen by many students at all levels of education as a very difficult subject to understand and to study. This has made a lot of students to dislike Mathematics as a subject and so perform poorly in the course. The purpose of the research was to improve positively the attitude of Bongo Senior High School Home Science Form One students towards Mathematics and create a platform for students to communicate and share their ideas among themselves, to enable them understand concepts of Mathematics. This was made possible by introducing students' discourse in the learning of Mathematics. The research revealed that, most students are able to learn Mathematics very well when they interact with their peers, indicating that one good way of leaning Mathematics is through students' discourse.
\end{abstract}

Keywords: Student Discourse, Bongo Senior High School, Curriculum Assessment, Home Science, Pre - Project Survey, Post - Project Survey

\section{Introduction}

A careful study of Bongo Senior High School Home Science Form One class revealed that students did not have interest in Mathematics as a subject and hence performed poorly at the end of their first and second term examinations. Many of these students did not want to have anything to do with Mathematics after their classes each day. Students' interest in mathematics and beliefs in the utility of the mathematical knowledge in their future career or their everyday life are important. Belief systems are one's mathematical world view, the perspective with which one approaches Mathematics and mathematical task. One's belief about mathematics can determine how one chooses to approach a problem, which techniques would be used or avoided, how long and hard one would work on it, and so on [1-2]. It was for this reason that attention was drawn to use students discourse to enhance the learning of Mathematics.

Most empirical demonstrations in literature revealed a positive correlation between student's attitude towards mathematics and their mathematical results [3]. Whereas in the case of Bongo Senior High School Home Science One class, a lot of students had a negative attitude towards mathematics however, they were able to use mathematical concepts to yield results in practical subject areas such as Food and Nutrition. This initiative was an indication that, when Mathematics is made practical and discourse is involved, students would understand the concepts better and would be able to apply it any time.

At the end of the study, the outcome determined that student discourse should be encouraged in Bongo Senior High School (SHS1) Core Mathematics class. The entire research focused on how to improve student's ability to verbalize their Mathematical ideas. Traditionally, Mathematics instruction includes a lot of teacher discourse and paper-pencil work by the students. As researchers, the main interest was to offer students more opportunities to actively participate in the learning that would be taking place and also take part in class discussions. It is important for students to be able to show their Mathematics ideas on paper as well as to be able to appropriately express their mathematical ideas verbally. Along with this idea was the importance of being able to listen to others, understand the language and vocabulary, and be able to participate in a meaningful conversation about Mathematics. 
As a result 'Improving student discourse' has been our main motivation since several situations abound in mathematics classrooms where only selected students had voiced their mathematical ideas. This is evident that many mathematics classrooms operate in this manner, not at the fault of the teacher, but rather this was just the nature of many students. There always seems to be a handful of students who participate fully in mathematics class, all other students remain silent. However, it is always good for teachers to hear from all students. This would help to assess students understanding of mathematical concepts. Thus, the objective for the research was to set the tone in the classroom for all students to have the opportunity and ability to share their ideas.

\section{Relevant Literature}

Cooperative learning is described as a small group of students working together on a common learning task with each student playing a unique role of helping group member to achieve this common goal [4]. Therefore, cooperative learning begins with the formation of groups into teams of students. In one study, Whicker employed 31 High School Junior and seniors students divided into two classes where one class studied material cooperatively and the other class studied independently [5]. Their cooperative groups consisted of five members and included one student from the top four of the class, one student from the bottom four of the class, and three students from the middle half of the class. And using surveys they found that most of the students indicated that they liked working in groups and getting help from other students. In the study conducted bt Petit, it is a known fact that in most Mathematics classrooms the discourse which takes place is mostly dominated by the teacher, and the language typically offered by the teacher focuses on the rules and presentation of skills necessary for students to learn a particular objective [6]. More recently, there has been a shift in focus to allow more student conversation and inquiry to take place during the course of a lesson.

In line with this, we are much interested in engaging students in more meaningful, inquiry-based discussions, with the main aim of increasing student learning. Additionally, the research would like to establish a learning environment that encourages all members of the class to become active participants in the conversations of focus. It is evident that in most Mathematics classes, it is rare for a student to have dual strengths in both their written Mathematical communication and in their oral communication. This research therefore focuses on increasing student learning through improved student discourse, and it is believed that some written communication may be involved in that process. Another related study indicated that, writing is emphasized as a way to aid students in learning to think and talk mathematically. According to them writing has been a traditional source of communication between students and teachers but could also be a preparation for students to take part in a discussion with the teacher, peers, or the entire class [7]. In their analysis which included sources of data such as; participant observations, student interviews, audio taping of students working in groups, and examining written work. They concluded that "rich learning experiences are possible when writing is used as a way to prepare students for group discussions in Mathematics". Their research further indicated that learning how to write helps to improve one's ability to talk mathematically. They however observed that there is the need to understand what one is always writing since it helps others to appreciate the mathematical concepts being put forward. For them the language of Mathematics is universal and important as much as writing and understanding its concepts.

Similar in a year - long study, Baxter concluded that allowing time for students to write journals in class revealed a lot more mathematical ideas than what was offered during class discussions [8]. His analysis of the students' journals identified multiple instances where the students were able to explain their mathematical reasoning, revealing their conceptual understanding, ability to explain, and skill at representing a problem. The promise of writing is that it offers an alternative to the visions of classroom communication that are strictly oral in nature. It is evident that Baxter's ideas are valuable, but it can be observed that the most compelling testimony for how discourse can improve mathematical thinking has also been endorsed most especially from students' interviews [7].

Prior to this study, students were put in small groups and asked to think about a problem or skill and independently attempt a problem solving strategy and possible solution. Students knew the expectations that the teacher had for them, which included being ready to contribute to a group discussion. This is indeed an innovative way of making students to understand the concepts of Mathematics. The prewriting activity gave the students the time to think independently about the problem and form their own opinions or strategies. Then when the group convened, whether it was a small student group or an entire class, the students had the opportunity to become comfortable with the problem or skill and formed the ideas that they felt were important to share with the group. Of the group of students that participated in this study, over half reported that being able to share written work with a group increased their understanding of the Mathematics problems. Students in the class used many different approaches to solve the same problem. After viewing each other's' ideas, students indicated that they might like to use another student's idea if given the chance to try the problem again. Additionally students found that, listening to their classmates was often just as helpful if not more helpful as listening to the teacher's explanation.

According to a study by Anderson, sharing research findings on students writing path improves communication in an elementary mathematics Classroom [9]. Using data from survey responses, problem solving scales, and rubrics they found that as they continued to make efforts to involve the 
entire class in generating the ideas of a lesson; student writings and mathematical verbal presentation also improved. They further revealed that teachers could be strong leaders and gentle guides. As a teacher, it is important to be the person to trigger the students' mathematical thinking but then let them be the persons working towards a discovery. A teacher' aim should be to guide, prompt and redirect ideas when necessary [9]. Therefore felt that an effect of offering more time for student discussion was for them to be able to better develop their own ideas and use the ideas offered by their peers, thus making mathematics more personal and meaningful for students. In addition, student discourse in mathematics provides teachers the ability to pose questions that sparks students' interest and thought. It is therefore important that questions posed in the classroom should be of interest to the students. This is usually possible when real life situations are explained to students before the question is posed.

Also, in many empirical investigations into how to improve the learning of Mathematics, formative assessment have been considered as one of the key strategies which goes with student discourse and can be used to help students learn Mathematics. The Formative assessment is a process of gathering evidence within the stream of instruction in order to inform teaching and learning [10]. To be considered formative, the evidence must be elicited, interpreted, and used by both teachers and learners [11-12]. Formative assessment further involves getting the best possible evidence about what students have learned and then using this information to decide what to do next. In a classroom that uses assessment to support learning, the divide between instruction and assessment blurs. In contrast, summative assessment is used to evaluate progress and achievement, assign grades, and appraise programs.

According to a study Leahy, everything students do such as conversing in groups, completing group project, answering and asking questions, working on projects, handling homework assignments, even sitting silently and looking confused is a potential source of information about how much they understand [13]. Consequentially, when classroom practice is based on formative assessment, teachers and students together develop a framework for what can be expected in students' learning, for what it means to move towards intended Mathematics learning goals, and for a common goal of continuous and progressive learning. Formative assessment is therefore a crucial tool for improving classroom practice and students' performance [6]. It is a strategy that involves three interrelated activities such as: (1) engaging students in tasks and activities that provide insights into their thinking; (2) teachers and students listening and analysing student discussions and artefacts interpretatively, not just from an evaluative perspective; and (3) implementing instructional strategies designed to engage all students in tasks, activities, and discussions [14]. He further suggested the reasons to ask questions in a classroom is to cause thinking and to provide information for the teacher about what to do next. In questioning, the task should be selected based on its ability to reveal students thinking and understanding around important mathematics concepts and practices. In addition, teachers should consider the potential of a task to reveal student progress along a developmental progression and its potential to elicit misconceptions, and common errors. Engineering effective classroom discussions, questions, and learning is also dependent on both teacher's and student's ability to listen interpretatively. That is, not just listening for the right answers but listening for evidence about student thinking to inform the next instructional steps. High engagement classroom environments appear to have a significant impact on student achievement. Therefore, when students are highly engaged, they are absorbed in activities, tasks, and discussions using techniques such as; think-pairshare, wait time, cold calling, sharing student generated solutions, and all student response systems such as mini white boards and exit cards. These and other instructional strategies provide teachers many opportunities to check for understanding during or right after a lesson, rather than waiting for homework, quizzes, and tests for evidence of what sense students are making of the Mathematics.

\section{Methodology}

The study commenced with a perusal of results of Bongo Senior High School students performance in core Mathematics. This revealed that the Home Science class performed poorly thus necessitated its adoption for the study in other to enhance their ability to learn the subject. Students were then asked to complete a pre-project survey questionnaire.

Subsequently, the students were placed in five groups based on their previous curriculum assessment scores. Each group consisted of students from the top $10 \%$, students from the middle $10 \%$ and students from the bottom $10 \%$ as in a study [5]. Since the class was made up of 50 students, students in the top $10 \%$ belonging to each one of the groups were made the leaders of the groups. The students remained in these groups for the first four weeks of the project. At each day of class, students were taught a Mathematics topic at the end of which problems would be given out to be solved in groups. On every Thursday of each week, students were given a review sheet, with the answers given, to make sure that each member of the group understood how to work each question. This review sheet consisted of problems similar to the homework problems from the previous weeks.

Two different types of individual assessments were given during this project: four curriculum assessments and five state standard assessments. Curriculum assessment 1, 2, 3 and 4 consisted of 20 open-ended items involving various types of computation and problem solving. There were 100 points possible for each assessment, and partial credit was awarded for any correct but incomplete answers. Curriculum assessment 2 consisted of 10 open-ended items and was 50 points possible with partial credit awarded for any correct but incomplete answers.

A group reward system was set up based on the curriculum 
assessment scores of students. Each student was given a baseline score on their previous curriculum assessment average score (before the project began). During the teacherformed group period, data was collected on scores on curriculum assessments 1 and 2 and three different state standard assessments.

On the five week of the project, students were then divided into groups of their own creation. During this studentformed group period, data was collected on scores of curriculum assessments 3 and 4 and two different state standard assessments. The same group reward system was used as was used for the teacher- formed groups. The class average on each curriculum assessment was compared to the class average before the project began. For each state standard assessment, data on the performance of students before the project was compared to student's performance after the project.

During the first week of the project, students were randomly selected to answer a specific set of interview questions (see Table 2). Following the completion of the project students were asked to complete a post- project survey (see Table 3). The surveys and interview responses were used to help determine how students' attitudes changed during the cooperative group learning process.

\section{Results and Findings}

This action research focused on only Home science class of Bongo Senior High School (Form one). The class was made up of 50 students out of which 36 were females and 14 were males. Each day of teaching during this action research project began by discussing and going through any student questions that arose from the previous day's problems. Then, a short introduction was given to the students about the new concept. The majority of the class time was used for cooperative group work. Students worked together on a specific set of problems from the textbook. In some circumstances, the students were given general instructions about a topic and allowed to discuss and formulate their conclusions. These conclusions then were shared with the rest of the class until everyone agreed upon a final accepted conclusion. Generally, this type of activity worked well when all students experienced some type of success at the beginning of the activity.

\subsection{Performance of Students Before the Research}

Performance of students before the research revealed that after their end of first term examination, the highest grade in Mathematics was C4 and four (4) persons representing 4\% of the total population of students had this grade. In this same term, sixteen (16) students representing $32 \%$ of the entire student population had F9 in the Mathematics examination.

Results for second term examination also revealed that the best grade for Mathematics was B3, however, one person representing $2 \%$ of the students population had this grade and fifteen people (15) representing $30 \%$ of the total students had F9. Below is a summary of results of students before the research.

Table 1. SUMMARY OF RESULTS BEFORE RESEARCH.

\begin{tabular}{|c|c|c|c|c|c|c|c|c|c|}
\hline RESULT & A1 & B2 & B3 & $\mathrm{C4}$ & $\mathrm{C5}$ & C6 & D7 & E8 & F9 \\
\hline FIRST TERM & & & & 4 & 6 & 6 & 7 & 11 & 16 \\
\hline SECOND TERM & & & 1 & 3 & 7 & 4 & 10 & 10 & 15 \\
\hline
\end{tabular}

The table above indicate results of students in their first and second term examinations conducted before the research. Data summarised in the table revealed that performance of students in Mathematics was very poor with about $32 \%$ of students failing in both first and second term examinations.

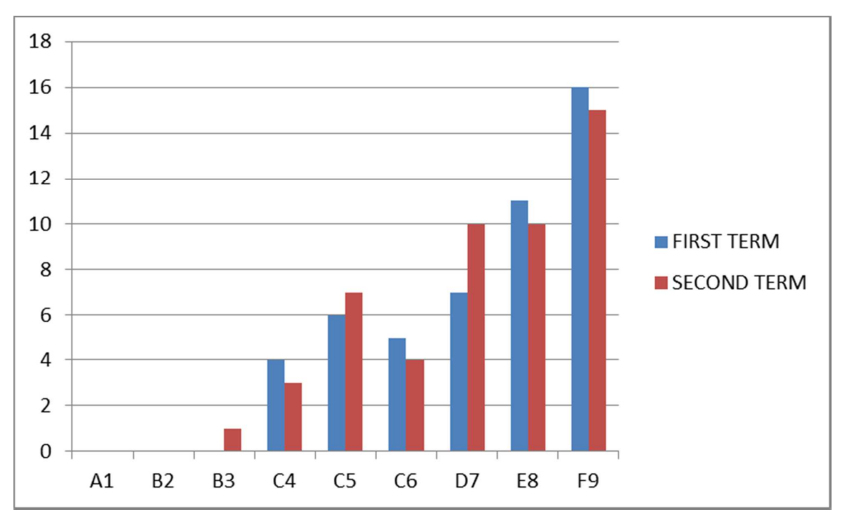

Figure 1. NUMBER OF STUDENTS AGAINST GRADES SCORED IN EXAMS BEFORE RESEARCH.
The histogram above illustrates the performance of students in Mathematics in their first and second term examinations before the research work was conducted. The total number of students was plotted against the grades scored in the two examinations. The blue bars represents the first term examination whilst the red bars represents the second term examination.

\subsection{Attitude of Students Towards Group Work in Maths Class}

In other to have an idea of how students feel about Mathematics and using group work to learn Mathematics, each student was asked to complete a pre- project survey questionnaire. The students were required to indicate whether they Agree, disagree or remain neutral to the questions asked. The table below indicates the number of students who responded (Agree, Neutral or Disagree) to the questions. 
Table 2. STUDENT PRE - PROJECT SURVEY RESPONSES

\begin{tabular}{|c|c|c|c|}
\hline QUESTION & A & $\mathbf{N}$ & D \\
\hline Do you like Mathematics as a subject? & 12 & 4 & 34 \\
\hline Do you like to work in groups in Mathematics class? & 15 & 30 & 5 \\
\hline Do you ask questions of others when you work in a group? & 28 & 14 & 8 \\
\hline Do Others in the group ask me questions when we work in groups? & 28 & 15 & 7 \\
\hline Do you have more confidence to try problems when you work in group? & 21 & 19 & 10 \\
\hline Working in a group helps me understand the concepts better & 15 & 20 & 15 \\
\hline Working in a group helps me get the work completed on time & 34 & 4 & 18 \\
\hline Working in groups helps me to learn quicker and retain more for the tests. & 12 & 7 & 31 \\
\hline When I work in a small group, everyone is encouraged to contribute. & 15 & 20 & 15 \\
\hline When I work in a small group, ideas and opinions are treated with respect. & 14 & 10 & 26 \\
\hline I am comfortable asking the teacher questions if I don't understand something. & 12 & 15 & 23 \\
\hline I am comfortable asking a group member questions if I don't understand something. & 16 & 10 & 14 \\
\hline
\end{tabular}

KEY: Agree - A.

Neutral $-\mathrm{N}$.

Disagree $-\mathrm{D}$

Table 3. STUDENT POST-PROJECT SURVEY.

\begin{tabular}{llll}
\hline QUESTION & A & N & D \\
\hline I like to work in groups in Mathematics class & 32 & 12 & 6 \\
I ask questions of others when I work in a group & 44 & 2 & 4 \\
Others in the group ask me questions when I work in a group & 43 & 3 & 4 \\
I have more confidence to try problems when I work in groups & 45 & 1 & 4 \\
Working in a group helps me understand the concepts better & 46 & 2 & 2 \\
Working in a group helps me get the work completed on time. & 47 & 2 & 1 \\
Working in groups helps me learn quicker and retain more for the tests. & 44 & 3 & 3 \\
When I work in a small group, everyone is encouraged to contribute. & 42 & 5 & 1 \\
When I work in a small group. Ideas and opinions are treated with respect. & 21 & 9 & 3 \\
I am comfortable asking the teacher questions if I don't understand something. & 32 & 10 & 8 \\
I thought that working in small groups was too noisy during class. & & 8 \\
\hline
\end{tabular}

KEY: Agree - A.

Neutral $-\mathrm{N}$.

Disagree - D

\subsection{Performance of Students After the Research}

Performance of students after the research revealed that, after their first assessment, the highest grade in Mathematics was B2 and three (3) persons representing $6 \%$ of the total population of students had this grade. In this same assessment, only one (1) student representing $2 \%$ of the entire student population had F9 in the Mathematics assessment.

Results for second assessment also revealed that the best grade for Mathematics was A1, however, two (2) persons representing $4 \%$ of the student population had this grade and the least grade recorded was D7. Below is a summary of results of students after the research.

Table 4. SUMMARY RESULTS OF ASSESSMENTS AFTER RESEARCH.

\begin{tabular}{llllllllll}
\hline RESULT & A1 & B2 & B3 & C4 & C5 & C6 & D7 & E8 & F9 \\
\hline ASSESSMENT 1 & & 3 & 9 & 14 & 4 & 12 & 4 & 3 & 1 \\
ASSESSMENT 2 & 2 & & 7 & 18 & 9 & 4 & 10 & & \\
\hline
\end{tabular}

The table above indicate results of students in their first and second assessments conducted after the research. Data summarised in the table revealed that performance of students in Mathematics improved tremendously with only one person failing in both assessments conducted after the research.

The histogram above illustrates the performance of students in Mathematics in their first and second assessments after the research work was conducted. The total number of students was plotted against the grades scored in the two assessments. The blue bars represent the first assessment whilst the red bars represent the second assessment.

The target group of students for this study was the Bongo Senior High School Home Science one Core Mathematics class, which was made up of fifty students. At the beginning, data on attitude and performance of students in Mathematics was collected and analysed to unearth the problem to be studied. Students were put into groups, with each group made up of five members. A topic in Core Mathematics was chosen and students were made to understand all concepts 
related to the topic. Students were then asked to split into their groups and real life problems related to the chosen topic was given out to all the groups to discuss and come out with solutions. This was closely supervised to ensure that all students were participating in discussions.

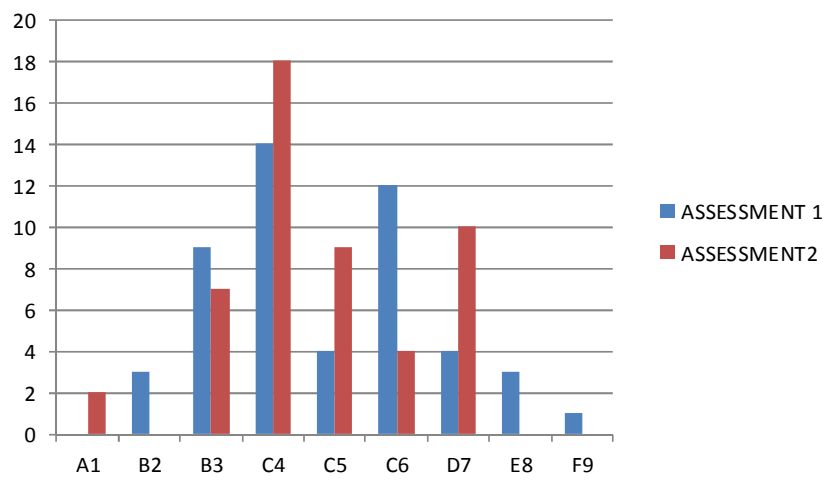

Figure 2. NUMBER OF STUDENTS AGAINST GRADES SCORED IN EXAMS AFTER RESEARCH.

Students were then given the opportunity to present and defend their solutions by arguing out all steps that lead to the final solution to each question. This started up discourse in the Mathematics class. Three other topics will be given to students and they will be required to follow the same process to discuss and understand the concepts with guidance from instructor.

At the end of the discussions, students will be assessed by means of oral and written examination to know if concepts have been well understood. Data on attitude and performance of students towards Mathematics will be collected and compared with the initial data collected at the start of the research. Based on results, conclusion will be drawn on how discourse has affected the learning of Mathematics.

\section{Conclusion}

Findings from this action research have revealed a massive improvement in student's attitude towards Mathematics akin to these studies [15-16]. These studies also found an increase in students' attitudes after working in cooperative learning groups. Gillies suggested that there is much to be gained by encouraging the use of this non-traditional pedagogical approach to teaching in classrooms, particularly when schools are trying to encourage the development of positive attitude towards learning.

Results and findings obtained from this research which was limited to only form one Home Science class of the Bongo Senior High School. The results have clearly shown that students discourse could play a vital role to aid the learning of Mathematics. Findings in this research indicate a change in academic performance after students discourse experiences contrasts with others' findings of decrease in academic performance as in a study conducted by Hohnson, where the use of cooperate learning was not associated with any increase in academic performance [17].

\section{Recommendation}

Though this research was only limited to fifty students of the Bongo Senior High School form one, the same outcome could be realised when a much larger population is to be considered. It would therefore be advisable if Mathematics teachers could adopt students discourse and form groups in class to teach Mathematics.

Ghana Education Service could also integrate students discourse into all lessons taught in the class since it is an efficient tool to help teaching and learning.

\section{References}

[1] Garofalo, J. (1989). Beliefs and their influence on mathematical performance. The Mathematics Teacher, 82 (7), 502-505.

[2] Schoenfeld, A. H. (1985). Mathematical Problem Solving. Orlando, FL: Academic Press.

[3] Butty, J. (2001). Teacher instruction, student attitudes, and mathematics performance among 10th and 12th grade Black and Hispanic students. Journal of Negro Education, 19-37.

[4] Kennedy, L., \& Tipps, S. (1994). Guiding children's learning of mathematics. California: Wadsworth.

[5] Whicker, Kristina, Linda, B., \& Nunnery, J. A. (1997). Cooperative learning in the secondary mathematics classroom. Journal of Education Research, 91 (1), 42-48.

[6] Petit, M., \& Zawojewski, J. (2010). Formative assessment in elementary school mathematics classrooms. In D. Lambdin (Ed.), Teaching and learning mathematics: Translating research for elementary school teachers (pp. 73-79). Reston, VA: National Council of the Teachers of Mathematics.

[7] Jacobs, G. M., Power, M. A., \& Inn, L. W. (2002). The teacher's sourcebook for cooperative learning: practical techniques, basic principles, and frequently asked questions. Corwin Press.

[8] Baxter, M. M. (2004). Self-Authorship as the common Goal of the 21 st-century education. In M. M. Baxter, \& P. M. King (Eds.), In Learning Partnerships: Theory and Models of Practice to Educate for Self-Authorship (pp. 1-36). Sterling VA: Stylus.

[9] Anderson, J. R., Reder, L. M., \& Simon, H. A. (1996). Situated learning and education. Educational Researcher, 25 (4), 5-11.

[10] Black, P. J., Lee, C., Harrison, C., \& Marshall, B. (2004). Working Inside the Black Box: Assessment for Learning in the Classroom. Phi Delta Kpappan, 86 (1), 8-21.

[11] Anderson, W. L., Mitchell, S. M., \& Osgoodh, M. P. (2005). Comparison of student performance in cooperative learning and traditional lecture-based biochemistry classes. Biochemistry and Molecular Biology Education, 33 (6), 387393.

[12] Dylan William. (2014). Formative assessment and contigency in the regulation of learning process. Toward a Theory of Classroom Assessment as the Regualation of Learning. Philadephia PA: American Educational Research Association. 
[13] Leahy, S., Lyon, C., Thompson, M., \& William, D. (2005). Classroom assessment: minute-by-minute and day-by-day. Educational Leadership, 63 (3), 18-24.

[14] Walmsley, A. L., \& Muniz, J. (2003). Cooperative learning and its effects in a high school Geometry classroom. Mathematics Teacher, 96 (2).

[15] Gillies, R. M. (2004). The effects of cooperative learning on junior high school students during small group learning. Learning and Instruction, 14 (2), 197-213.
[16] Walmsley, A. L. (2003). Cooperative learning and its effects in a high school geometry classroom. Mathematics Teacher, $96(2), 112-116$.

[17] Johnson, D. W., \& Johnson, R. T. (1999). Learning together and alone: cooperative, competitive, and individualistic learning. Boston: Allyn \& Bacon. 